\title{
GENDER*UCK: Reframing gender \& media art
}

\author{
Oliver M. Gingrich \\ Bournemouth University \\ London, United Kingdom \\ olivergingrich@gmail.com
}

\begin{abstract}
Media arts question boundaries and definitions of societal concepts, including notions and conceptions of gender. As part of a new series on media art and gender by the media art platform Art in Flux, Gender ${ }^{*} u c k$ raised questions on media art and gender representation. Hand in hand with a talks event at The National Gallery, Gender*uck presented the next generation of artists investigating boundaries of gender concepts in an online exhibition. These young artists investigate gender fluid representation in diverse media: Where does technology empower, where does it limit our conceptions of self and other? How can we look beyond binary forms of representations in the context of the binary and digital in new media. In a tech-centric world of media abundance, what roles can artists play in questioning gender norms, gender representations and gender normativity?
\end{abstract}

Media art. Gender norms. Non-binary. Queer. LGBTQ. Diversity. Transformational.

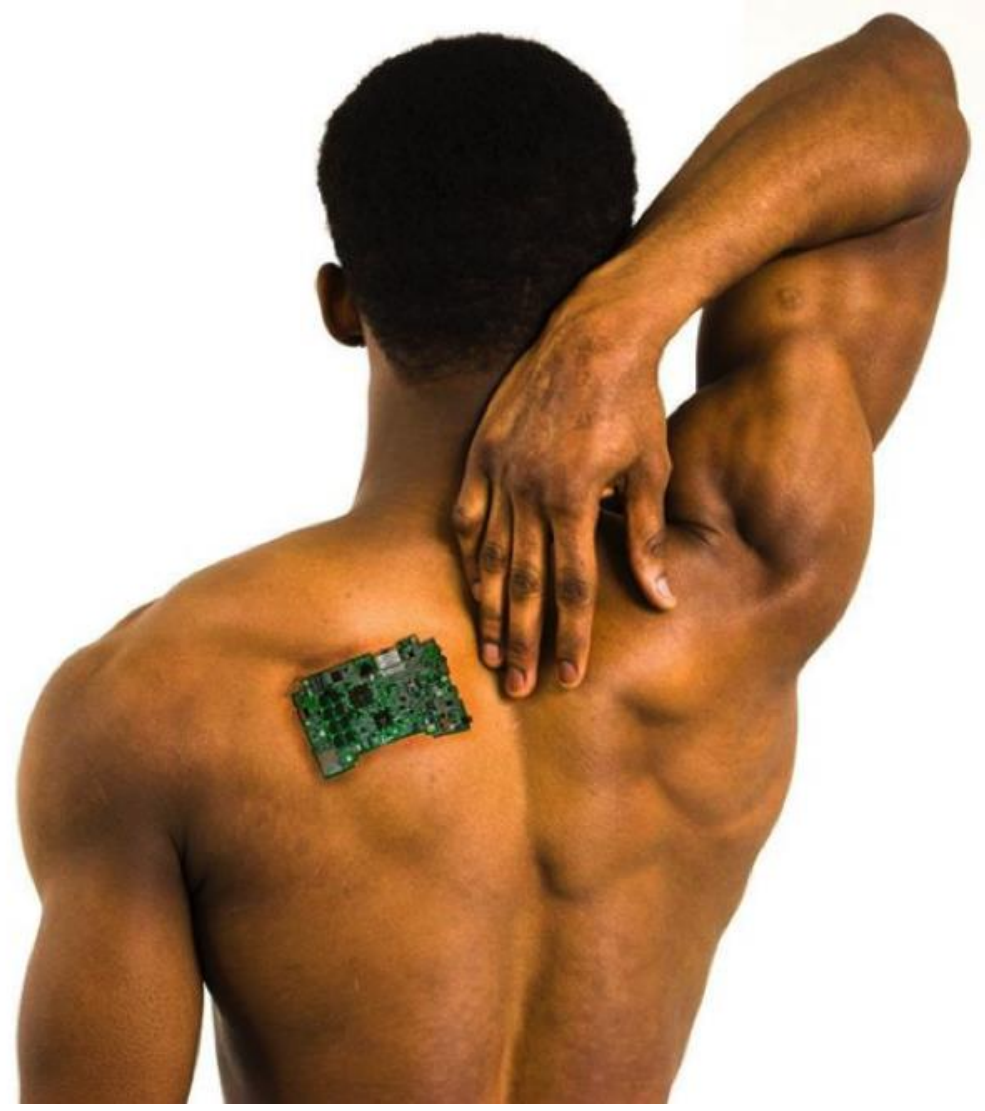

Figure 1: Oliver M Gingrich. Android Mythologies. 2018 


\section{INTRODUCTION}

Genderfuck is a portmanteau which refers to the self-conscious effort to "fuck with" or play with traditional notions of gender identity, gender roles, and gender presentation." The title of this talk and online exhibition is programmatic, in presenting gender not as fixed, but as fluid, open for interpretation, discovery, and self-interpretation. 99 years after Man Ray took a photo of his friend Marcel Duchamp as Rrose Sélavy, gender continues to remain as personal as it is political. In 2020, the recently inaugurated National Gallery X, a new forum for collaboration between art, science and technology, the first in a series of talks by media art platform Art in Flux, raised important questions on heteronormativity and its subversion, gender fluidity and its representation in the context of media art.

Against the backdrop of a UK-wide national lockdown, National Gallery X, a new collaborative studio by the National Gallery and King's College, supported by Google Arts and Culture orchestrated and hosted a discussion on media art practice, and gender. The talk, framed by an online exhibition held by the media arts platform Art in Flux, presented queer and non-binary media artists, as well as researchers in the field. Curated by Art in Flux co-founder Oliver Gingrich, the discussion reached beyond binary conceptions of gender. This paper discusses contemporary media artists and their diverse strategies in approaching gender in the context of new media.

While Paul Kindersley's art dismantles gender stereotypes for instance in his feature length films inspired by the National Gallery's world-famous art \& heritage collection, media artist Birgitta Hosea questions gender roles in her animation and performance practice.

Paula Callus is presented her work with Nigerian women artists from an anthropological angle focusing upon the culturally located experiences of gender. For this master thesis at University of the Arts London, James Nasmyth presented a photobooth that subverts gender conceptions. Peju Alatise is a Nigerian artist, who presented one of her pieces on the difficult social and political situation of women in Nigeria.

Artist Jake Elwes explores alternative gender representations in the context of machine learning algorithms. What happens when computers try to find patterns of beauty beyond gender concepts and their mathematical confinements. Ro Greenberg's investigates non-binary concepts through their art and music creation.

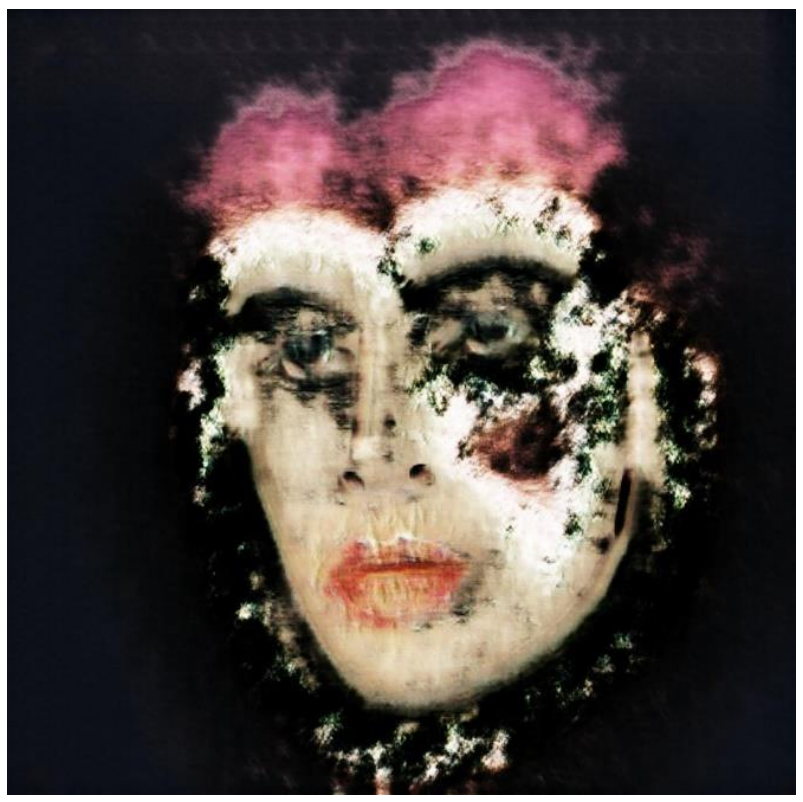

Figure 2: Jake Elwes. Zizi 2019

Finally, Drucilla Burrell investigates aesthetics beyond gender definitions through her lockdown fine art photography series created during lockdown, inspired by classic portraits as seen at the national gallery. Together these artists discuss limitations, possibilities and the future of technology for art forms beyond gender in the context of new media. This paper will present their art works, discuss nuances and differences, as well as shared tropes and influences between them. At the same time, the paper will provide an insight and outlook into the next chapter and future of the talks series, introducing 'reclaimed' an exhibition by art in flux on underrepresented groups in the media arts.

\section{QUEER STORYTELLING}

Paul Kindersley, born in Cambridge in 1985, has exhibited globally including the Hayward Gallery's Drag: Self-portraits and Body Politics (Hayward Gallery 2018), Vienna, Paris, Rejkjavik and elsewhere. His art explores diverse narratives of self-expression, for instance through his make-up youtube tutorials, and recently in his feature films, that are heavily influenced by the National Gallery's collection. Kindersley's feature films 'Das Spiel der Hoffnung (2017), Orlando at the present time (2018) and The Burning Baby (2020) introduce non-linear narratives, gender fluid characters through visually eclectic, pervasive and powerful compositions. 


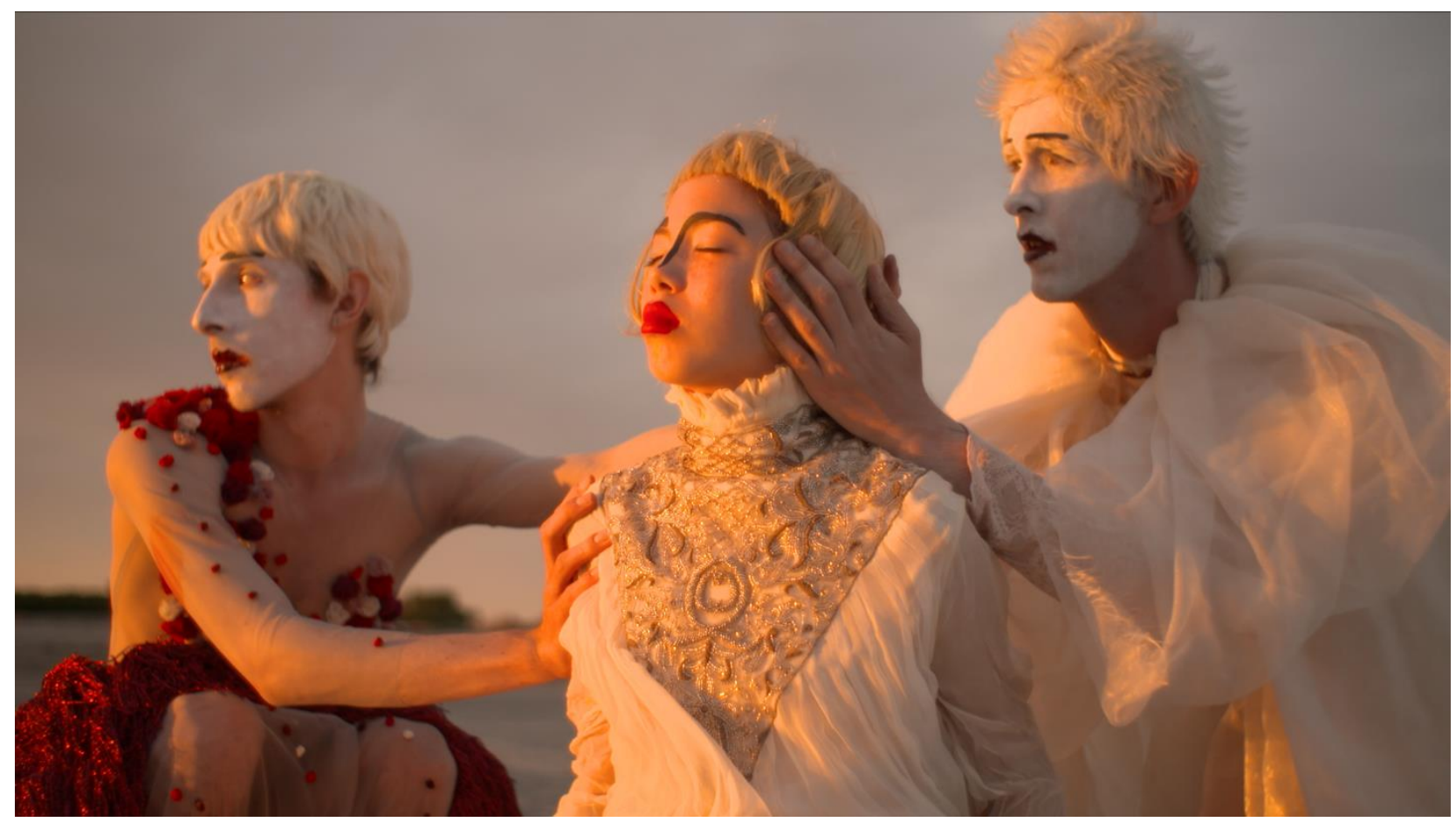

Figure 3: Oh! And Twins at the Beach, Paul Kindersley 2017

Paul Kindersley's narratives are inspired by playful re-interpretations of classic visual storytelling such as found at the National Gallery and their collection. The characters and happenings Paul Kindersley stages reach beyond any gender norms, and present queerness in a multitude of different ways. Through powerful visual compositioning, dramatic staging and epic, captivating camera work, Paul Kindersley's art tells its own stories, reflecting on a canon of dramatic visual vocabulary, while articulating its own positions of beauty, gender and art.

Ro Greengrass, the artist Ro Greenberg's first film 'Down where the Seafolk live' is a documentary on trans artists and their singing voices. The metaphor of Hans Christian Andersen's The Little Mermaid, in which a mermaid sacrifices her voice for the gift of transformation, echoes the artists the documentary follows. Created by the artists Ro Greenberg and Maddy James, both graduates of Goldsmiths, University of London's Department for Creative Media and Cultural Studies, the film is lyrical, poetic and important in following the trajectories of these young artists within a personal, intimate, and deeply moving setting. A trailer for 'Down there the seafolk live', was premiered at Gendertuck, and the full film is now featured at Art in Flux' Reclaimed exhibition, launched at National Gallery X on the 30th of March 2021.

\section{GENDERED SPACES}

Researcher Dr. Paula Callus' talk 'Gendering Spaces: Women and Art in Nigeria' presented work by the artists Wura-Natasha Ogunji, Peju Layiwola, Ngozi Schommers and Peju Alatise while asking questions about Nigerian female artists and their practice, including a focus on women's rights. Paula Callus' presentation emerged from research for the Arts and Humanities Research Council funded project 'ArtoP: The visual articulations of politics in Nigeria'. Her research focuses on the documentation and archiving of diverse art practices reflecting politics and political debates of everyday life in Nigeria. Ogunji, Layiwola, Schommers and Alatise, are important contributor to an artistic discourse that expresses the politics of gender and identity across Nigeria's multitude of cultural spectra:

Nigeria is a rich and diverse country encompassing different religions, cultural identities and over 400 languages such as Igbo, Yoruba, Hausa or Edo, these backgrounds and contexts influence the politics of gender. Social, political and economic conditions of women 'are themselves historically [and geographically] specific and, therefore, cannot be framed in terms of gender alone.' (Mills 2006). Paula Callus presented work by Ogunji, Schommers, Layiwola and Alatise, drawing out conceptual connections between space, gender and politics. 


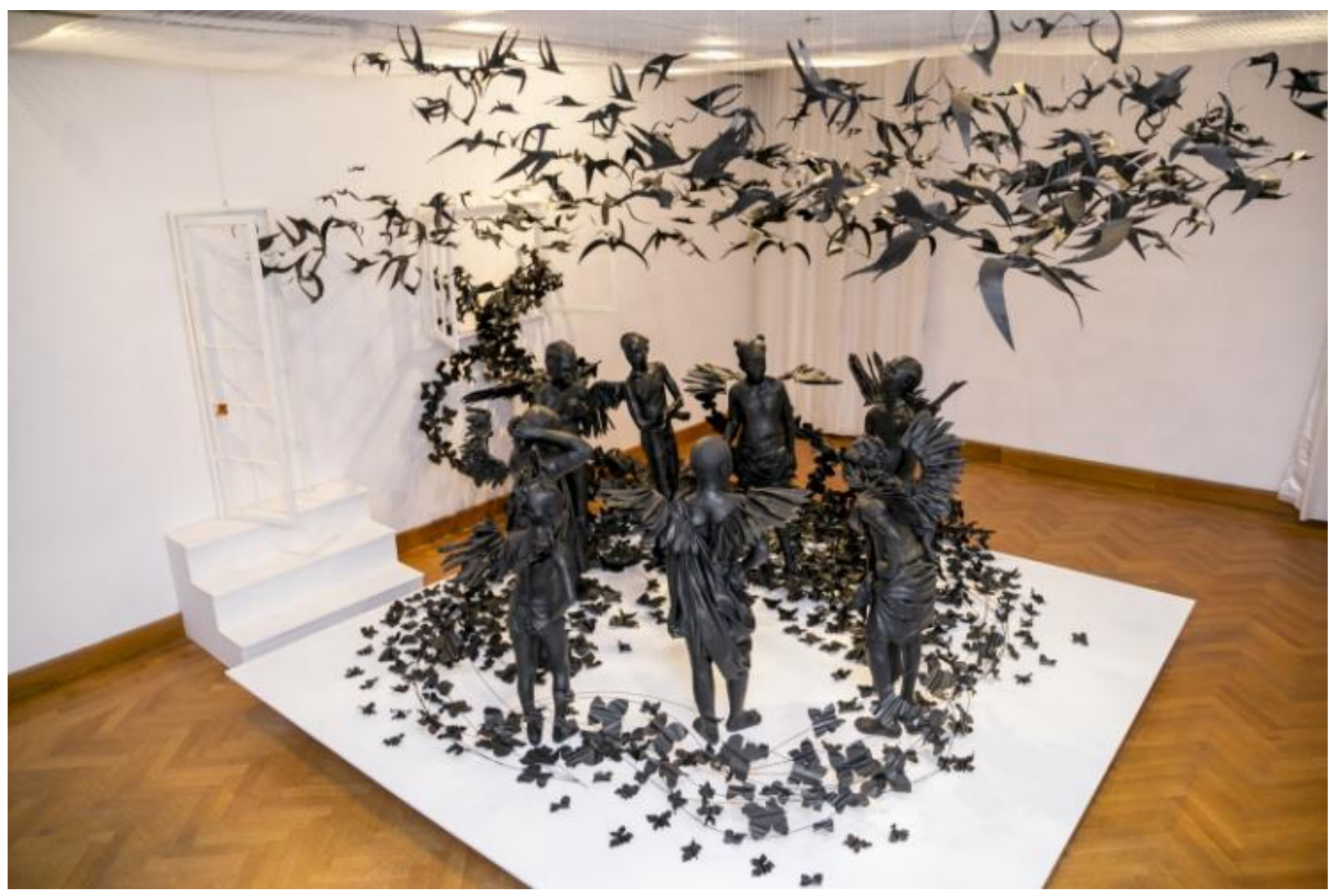

Figure 4: Peju Alatise, 'Flying Girls', 57th Venice Biennale, 2017

The artist Peju Alatise, a leading contemporary artist, works across different media and disciplines including sculpture, literature and architecture. Peju not only was nominated for the ANA/ Flora Nwapa Prize for Women Writing, her sculptural work was exhibited at the 57th Venice Biennale, and she is the 2017 winner of the FNB Art Prize. The work Peju Alatise presented at the Gendertuck exhibition, a reading and film, describes the plight of young Nigerian women, and the lack of protection from being married against their will at a young age, a cause she actively fights for through the The Child Not Bride campaign, of which she has become an active proponent.

Peju Alatise's sculpture and literature questions discriminatory Nigerian power and political structures, systematic discrimination of women, and her voice provides a sign of hope that a different future is possible. At Gender*uck, Peju Alatise provided further context to conceptions of gender through a transmedia approach, that encompassed different art genres, united in their vocal and empowering critique of gender politics in Nigeria and globally.
The artist James Nasmyth art and research project 'The Dark Room' consists of an ephemeral, transient space, a physical photobooth, in which participants can photograph intimate self-portraits. The participating audience is invited to take pictures and to share the results as single polaroid prints within the installation. Conceptually, the art work plays on the ideas of reproducibility, the selfie-culture, the ideas of selection, and stands as an open invitation to create alternative forms of queer aesthetics. Designed for club spaces, James Nasmyth calls 'The Dark Room' "a human-centred response to the heteronormative, sometimes racist and/or sexist algorithms built into our digital networks, which censor and control the content we share."

\section{MEDIATING GENDER}

The artist Birgitta Hosea is world-wide renown for her performative practices, which frequently involve drawings, animations and light. Having taught in Azerbaijan, the United States, across Europe and in China where is currently a visiting professor, her practice revolves around conceptions of presence, gender, often subverting the male gaze. 


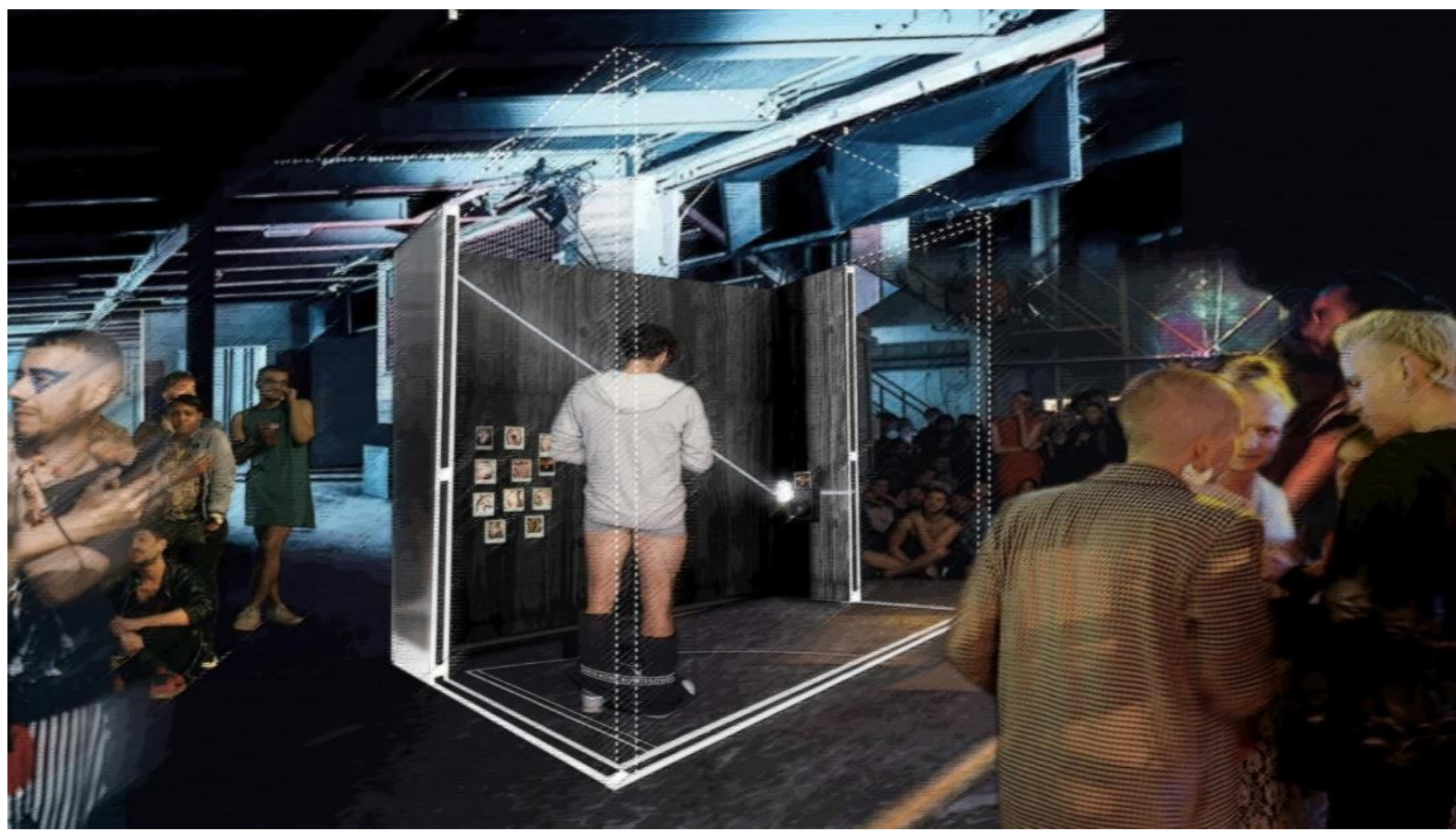

Figure 5: James Nasmyth, The Dark Room, 2020

In the performance 'Out There in the Dark' Birgitta Hosea transforms her own body into a human sculpture, that is projected onto, turning her body into an animation, a sculpture, a performance. Animation replaces the face of the artist by a doll that is lip syncing, to dialogues from the Hollywood classic 'Sunset Boulevard' (1950). The gaze of the camera is actively performed, intensely experienced by both the artist as well as the audience, that turns not just into a bystander but a
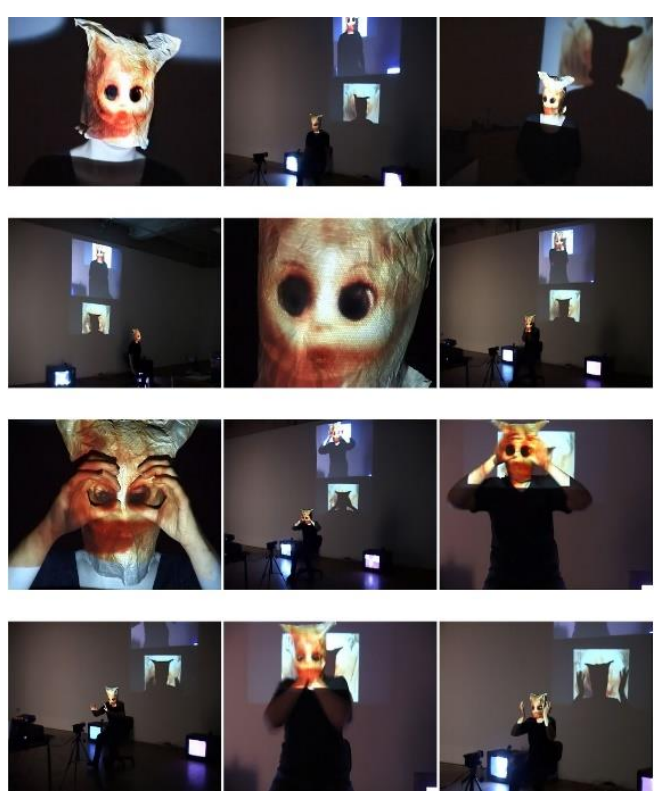

Figure 6: Birgitta Hosea, Out there in the Dark, 20082013 voyeur. Just as the Hollwood film Sunset Boulevard presents women as hysterical, the performance amplifies this soutext into the grotesque.

Objectifying animation practices, symbolic use of a doll, and the use of an assemblage of fragmented audio, transcend the leitmotif of this artwork: 'Out there in the Dark' explicitly challenges the male gaze by actively fragmenting and questioning the construction of femininity in Hollwood cinema.

The artist Jake Elwes is exploring genderfluid representations of beauty in the context of artificial intelligence (AI). The artwork 'Zizi - Queering the Dataset' actively critiques the absence of diversity and representation in machine learning training data such as the popular Celeb 250 dataset. Facial recognition algorithms regularly use machinelearning techniques, that rely on such heteronormative datasets.

As an artist, Jake Elwes challenges subconscious bias and discriminatory undercurrents in technology, as well as implicit stereotyping frequently performed by such systems. Without questioning the value systems that underpin Al, gender bias and sometimes discrimation seems to seep into our lives. Generative adversarial networks (GANs), a technique used by Google's 'Deep Dream' project, allows the creation of all new data sets through machine learning algorithms. With Zizi, Jake Elwes used Gan's to retrains neural network algorithms to include aesthetics and conceptions of beauty informed by genderfluid, queer performers. 
The Edinburgh Festival's curator Drew Hemmet described the project in this context of gender and fluidity: 'Zizi makes this aspect of drag explicit, through autonomously generated faces that are fluid and never still. Here, the permanent becoming of a GAN represents the fluidity, ambiguity and transition of drag artists.'

The Zizi artwork constantly shifts between queer performers, thereby playing with the idea of disturbance and disruption of inherent, invisible technological logic and agency. The sublime aesthetics of Zizi reach beyond the binary, into a sensual space of new aesthetics in which questioning gender norms results in evertransforming, possibilities of gender.

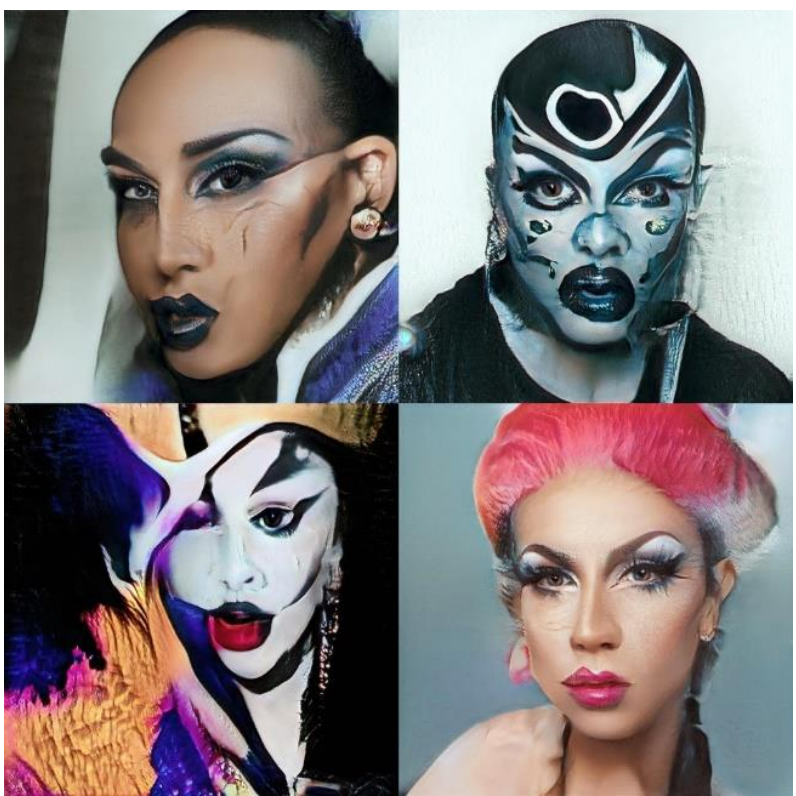

Figure 7: Jake Elwes. Zizi. 2020

\section{QUESTIONING GENDER REPRESENTATION}

In the context of the National Gallery, an institution that discusses gender representations in their collection critically, new artistic position such as developed by the artist Drucilla Burell help to question gender depictions in the context of classic portraiture. How is power conveyed visually? How is domesticity communicated within artworks in the collection of the National Gallery. Drucilla Burrell's new artwork, developed during lockdown with her partner, investigates visual strategy in the context of gender, power and communication.

With Gender*uck, various generations of artists, from diverse backgrounds expressed their own notion of gender through a mix of media and methods, all united in challenging binary modes of thinking. This discourse become even more relevant against the backdrop of the National Gallery, an important cultural institution that is leading by examples, by actively discussing misand underrepresentation of gender in their collection. National Gallery X's Co-Director Dr. Ali Hossaini expressed his support for this particular discourse on gender and contemporary media arts practices:

\begin{abstract}
'It's easy to forget the National Gallery's paintings were made by radicals. Damned by heresy, humanism, immorality and fiendish capacities to fool the eye, many of the Old Masters inspired controversy, rage and social change. As society convulses again, art is suddenly relevant on the street. Our descendents will decide which artists to remember. But National Gallery $X$ is joining the conversation - and finding its innermost spirit by giving voice to the radical artists of today who will be the Old Masters of tomorrow.'
\end{abstract}

In 2021, Art in Flux will continue to challenge under-representation by curating the exhibition Reclaimed, an exhibition that combines women in tech, trans, and non-binary artists, neuro-diverse artists, and artists from a range of different cultural backgrounds, operating on the fringes of mainstream art. Reclaimed will reclaim the space that marginalised groups are often excluded from. And while media art continues to be a marginalised genre within the contemporary art scene, initiatives such as Art in Flux's Gender*uck and Reclaimed exhibitions contribute to recent trends that diverse voices are increasingly being heard, recognised and represented within the media arts, and their cultural institutions.

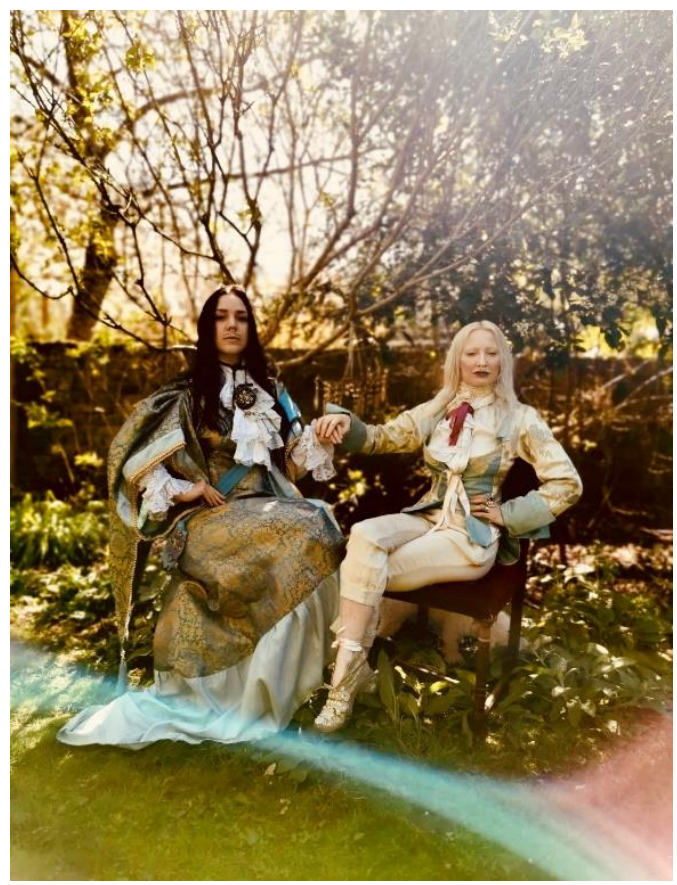

Figure 8: Drucilla Burrell: Little Versailles, 2020 


\section{REFERENCES}

Alatise, P. (2017) Flying Girls [Installation]. 57th Venice Biennale, Nigeria Pavillion.

Burell, D. (2020) Little Versailles [Photograph] London.

Elwes, j. Zizi. (2020) Video-art. [Exhibition] London.

Gingrich, O. Shemza, A., Almena A. (2020) Transformations: In: Weinel, J., Bowen, J.P., Diprose, G., and Lambert, N. (eds), EVA London 2020 (Electronic Visualisation and the Arts) 2020, pp.183-188. doi: 10.14236/ewic/EVA2020.34
Greengrass, R. (2020) Down There the Seafold Live. [Film].

Hosea, B. Out of the Dark [Installation and Performance], 2008-2013.

Kindersley, P. (2020) The Burning Baby [Performance].

Nasmyth, J. (2020) The Dark Room [Installation], London. 